\title{
Solar disinfection potentials of aqua lens, photovoltaic and glass bottle subsequent to plant-based coagulant: for low-cost household water treatment systems
}

\author{
Yonas Lamore $^{1} \cdot$ Abebe Beyene $^{1} \cdot$ Samuel Fekadu $^{1} \cdot$ Moa Megersa ${ }^{1,2}$
}

Received: 24 January 2018 / Accepted: 4 June 2018 / Published online: 19 June 2018

(c) The Author(s) 2018

\begin{abstract}
Unaffordable construction cost of conventional water treatment plant and distribution system in most developing countries makes difficult to provide safe and adequate water for all households, especially for the rural setup. Water treatment at the source can be the best alternative. Solar disinfection is one alternative among point of use treatments. In this study, aqua lens, photovoltaic box and glass bottle were used subsequent to plant coagulants to evaluate microbial reduction potentials. Laboratory- and field-based experiments were conducted from May to August 2016. The Escherichia coli, total coliforms and heterotrophic plate counts were used as indicator organisms. The result indicated that aqua lens (AL), photovoltaic box (PV) and glass bottle (GB) have high inactivation rate subsequently almost for all indicator organisms in short solar exposure time. Total coliforms were inactivated in $\mathrm{AL}\left(\mathrm{SD}=15.8^{\circ} \mathrm{C}, R^{2}=0.92\right)$ followed by $\mathrm{PV}$ inactivation temperature association $\left(\mathrm{SD}=11.6 \mathrm{C}, R^{2}=0.90\right)$, and the $\mathrm{GB}$ concentrator was inactivated $\left(\mathrm{SD}=10.9^{\circ} \mathrm{C}, R^{2}=0.70\right)$ at turbidity level of 3.41 NTU. As the study indicated, aqua lens coupled with Moringa oleifera coagulant can be an effective with minimum cost for household water treatment system. The study also concludes heterotrophic bacteria were more resistant than other types of bacteria in SODIS with similar exposure time.
\end{abstract}

Keywords Acrylic glass $\cdot$ Aqua lens $\cdot$ Moringa oleifera $\cdot$ Photovoltaic box $\cdot$ Solar disinfection $\cdot$ Water treatment

\section{Introduction}

Unsafe drinking water supply, inadequate sanitation and insufficient hygiene practice are the factors causing the major share $(88 \%)$ of all diarrhea cases. Diarrhea is a leading killer of children, accounting for nine percent of all deaths in 2015 (UNICEF 2016). About 6000 children underage five die every day, and a child dies at every $8 \mathrm{~s}$ from water-related disease around the globe. This accounts 19\% of total child deaths in developing countries (Gomez-Couso et al. 2009). It also causes malnutrition, with the subsequent consequences on physical development and susceptibility

Moa Megersa

moamegersa78@gmail.com

1 Environmental Health Science and Technology Department, Institute of Health Science, Jimma University, Jimma, Ethiopia

2 School of Natural Sciences, Department of Biology, Madawalabu University, Robe, Ethiopia to other infections (Gomez-Couso et al. 2009; Byrne et al. 2011; Fontan-Sainz et al. 2012).

Despite the fact that developing countries have large amount of freshwater resources, treatment plant construction and inappropriate treatment cost limit the distribution of the system at a household level. According to Bekele and Leta (2016), 51\% of Ethiopian rural residents depend on surface water without treatment. Although conventional water treatment improves water quality, studies have shown that household water treatment techniques could also be used to treat water (Sobsey et al. 2008). WHO estimated improving access to safe water and sanitation ought to forestall at least $9.1 \%$ of the international burden of ailments and $6.3 \%$ of all deaths (Byrne et al. 2011). Point of use systems refers to the range of water treatment methods including solar treatment, physical treatment, chemical treatment and combined treatment which treat water at the point of use by avoiding contamination during distribution, collection, transportation and storage (Sobsey 2002).

SODIS is a cheap and easy to use, environmental friendly and effective drinking water disinfection technology 
(Sobsey et al. 2008). The method treats contaminated water in transparent plastic bottles through exposure to sunlight for a minimum of $6 \mathrm{~h}$ (Byrne et al. 2011). Following the exposure time, the water is safe to be consumed as the microbial loads can be significantly reduced. SODIS technology enhances bactericidal effect of UVA electromagnetic region (wavelengths in the range of 320-400 nm) of solar radiation with synergism effect of heat (infrared wave) and in the presence of dissolved oxygen species for inactivation of pathogens in the water. UV radiation showed an adverse effect on microbial skill to achieve cellular respiration and generation of adenosine triphosphate (Bosshard et al. 2010).

Drinking water disinfection by natural and/or artificial sunlight is widely studied using plastic or/and glass materials by the aid of photoconcentrator catalysts for the inactivation of a number of bacteria (Helali et al. 2013). Light intensity of wavelength, solar exposure time, availability of dissolved oxygen, turbidity level and water temperature are major study variables that affect the efficiency of SODIS (Byrne et al. 2011).

The study aimed to compare the disinfection potential of (GB)-, (PV)- and (AL)-based SODIS disinfection using some indicator organisms like E. coli, total coliforms and heterotrophic plate counts by using $M$. oleifera as pre-treatment for turbidity reduction.

\section{Materials and methods}

\section{Experimental setup}

Laboratory- and field-based experiments were conducted from May 24, 2016, up to August 2, 2016, to investigate the solar disinfection (SODIS) potential of three concentrators (GB, PV and AL).

\section{Quality assurance}

During laboratory experiment, all activities were performed in line with laboratory quality standards. All sample bottles and glass wares were sterilized keeping standard time, temperature and pressure. Control sample was kept at room preventing from sunlight and high temperature exposure.

\section{Physical parameters}

\section{Turbidity removal test}

A turbidity removal test was conducted on natural surface water from Ginjo Gudru by using M. oleifera seed powder. Initially, the raw water turbidity level was 28.6, 30.7 and 45.6 NTU taken at different sampling times. The jar test apparatus was used in a turbidity removal experiment, whereby 10,30 and $50 \mathrm{mg} / \mathrm{L}$ dose of $M$. oleifera seed powder was added in each 1-L beaker containing the water samples at three turbidity levels, and the change was measured after $2 \mathrm{~h}$ with their control (Lea 2010).

\section{UVA irradiation measurement}

The solar irradiance was measured at different weather conditions from May 24, 2016, to August 2, 2016, consistently high between 645 and $1200 \mathrm{~W} / \mathrm{m}^{2}$ (Gomez-Couso et al. 2009; Giannakis et al. 2014).

$\mathrm{UV}_{\mathrm{A}}$ was measured within every 30 -min intervals (Reed 1997) from 12 up to $3 \frac{1}{2} \mathrm{pm}$ by calibrated solar taster and clear sky calculator with a central wavelength of $320-400 \mathrm{~nm}$ which provides data in terms of incident WUV/ $\mathrm{m}^{2}$. $\mathrm{Q}_{\mathrm{UV}}$ was calculated for comparison of solar test results (Helali et al. 2013).

It estimates the accumulated UV energy in the solar reactors per unit of treated water volume for given periods of time.

$\mathrm{QUV}=\sum_{n}^{u v} n-1 A_{r} / V_{t}\left(t_{n}-t_{n}-1\right)$

where $t_{n}$ is the experimental time for $\mathrm{n}$-sample, $\mathrm{UV}_{n-1}$ is the average solar ultraviolet radiation measured during the period $\left(t_{n}-t_{n-1}\right), A_{r}$ is the illuminated reactor surface, and $V_{t}$ is the total water volume.

\section{Dissolved oxygen}

Dissolved oxygen was one of the critical parameters in this study, and the initial dissolved oxygen availability was measured to compare with the final contents at different solar exposure times. All containers were agitated at 30-min intervals, to maintain oxygen equilibration within the water samples. By using dissolved oxygen measuring apparatus, the variable was measured at 30-min interval similarly to another variables (Burgess et al. 2007).

\section{Microbial indicator organisms}

\section{E. coli and total coliforms}

Membrane filtration technique was used for both total coliforms and E. coli, $3.81 \mathrm{~g}$ of membrane lauryl sulfate broth mixed with $100 \mathrm{~mL}$ of distilled water and sterilized at standardized time, temperature and pressure (Oxoid, Basingstoke, England) as ISO 9308-3:1999 and ISO 93081:2000 (Almeida et al. 2015). All samples were replicated and prepared at required dilution (0.1 and 0.01) since it is the 
standard dilution for surface water or rivers. One hundred milliliters of diluted sample discharged to vacuum pumper which contains filter paper with pour size of $0.45 \mu \mathrm{m}$ and $47 \mathrm{~mm}$ diameter. Finally, the filter paper transferred to sterilized petri dishes with $50 \times 12 \mathrm{~mm}$ diameter that contains absorbent pad already pipetted with $2 \mathrm{~mL}$ of culture media. After incubating at optimum temperature and time, colonies were counted to compare with initial load (Myers 2003).

\section{Heterotrophic plate counts}

The pour plate method or standard plate count method was used to determine heterotrophic plate count bacteria density. $2.35 \mathrm{~g}$ of plate count agar was mixed with $100 \mathrm{~mL}$ cool water and sterilized as standard; then, melted medium was kept in a water bath between 44 and $46{ }^{\circ} \mathrm{C}$ until used. The appropriate amount $(2 \mathrm{~mL})$ of diluted sample pipetted into the sterilized petri dishes for each different volume of diluted sample used $12 \mathrm{~mL}$ of liquefied media, and each dilution was replicated. The medium poured into the dish by gently lifting the cover just high enough to pour. Melted medium was mixed thoroughly with the sample in the petri dish by rotating the dish in opposite directions or by rotating and tilting the plates placed on a surface level inside the hood and solidify within $10 \mathrm{~min}$. Finally, dishes placed inverted to prevent condensation and seal in a plastic sheet, followed by incubation at $35^{\circ} \mathrm{C}$ for $48 \mathrm{~h}$ (Stillings and Herzig 1998).

\section{Chick-Watson model of microbial disinfection kinetics}

The inactivation efficiency of solar irradiation and water temperature was evaluated using natural surface water in different exposure times. The level of microbial inactivation was described by first-order Chick's law reaction number of microorganisms destroyed per unit of time which is proportional to the number of organisms in the form of log inactivation.

$\mathrm{d} N / \mathrm{d} t=-k * N \rightarrow \ln (N / N o)=-k * t$

$N / N_{O}=e-k . t \rightarrow$ reduction factor $(R)$

Log inactivation $=\log _{10} N_{t} / N_{O}$

Percent inactivation $=\left(1-N_{t} / N_{o}\right) \times 100$

Therefore, the relationship between log inactivation and percent inactivation is as follows:

Percent inactivation $=\left(1-\frac{1}{10 \log \text { inactivation }}\right) \times 100$

or

$\log$ inactivation $=\log \left(\frac{100}{100-\text { percent inactivation }}\right)$ where $N_{O}=$ initial (influent) concentration of viable microorganisms; $N_{T}=$ concentration of surviving microorganisms; $\log =$ Logarithm to base $10, t=$ time, $k=$ rate constant - this depends on disinfectant concentration, organism and temperature (Mcguigan et al. 1998).

\section{Solar disinfection methods}

\section{Glass bottle solar disinfection}

Figure 1a presents that half-blackened three glass bottles with size of $8 \mathrm{~cm}$ were exposed to UV light and heat at three different turbidity levels. The optical inactivation process was improved by wrapping reflective aluminum foils and coating a dark opaque substance at the rear half of the glass bottle. The glass bottles have $89-90 \%$ transmittance efficiency in the UVA (320-400 nm) wavelengths range, whereas transparent polyethylene terephthalate bottles transmittance might be as high as $85-90 \%$ in the same wavelengths range (Navntoft et al. 2008).

\section{Photovoltaic solar disinfection}

Figure $1 \mathrm{~b}$ shows that the bottom surface of the PV box is alone coated with semiconductor photocatalyst $\mathrm{TiO}_{2}$, while the top portion of the box was left; $92-98 \%$ transparent acrylic sheet was used to pass UV light through and fall on the $\mathrm{TiO}_{2}$ layer at the bottom surface to determine bacterial inactivation after exposure. Bacterial inactivation was calculated within the interval of $30 \mathrm{~min}$ from each turbidity category (Murugan and Ram 2018).

\section{Solar Reactor-Photocatalytic Reactions of TiO2}

Figure 1c presents a photon (hv) from the UV spectrum of the sun's rays fall on the $\mathrm{TiO}_{2}$; it produces an electron-hole pair as shown in the following reaction.

$\mathrm{TiO}_{2}+\mathrm{hv} \rightarrow \mathrm{TiO}_{2} \cdot\left(\mathrm{e}^{-}+\right.$hole $\left.{ }^{+}\right)$

The recombination reaction is

$\mathrm{TiO}_{2} \cdot\left(\mathrm{e}^{-}+\right.$hole $\left.{ }^{+}\right) \rightarrow \mathrm{TiO}_{2+}$ heat

The overall reaction of the photocatalytic reaction when water flows through it is:

$\mathrm{TiO}_{2}+\mathrm{hv}+\mathrm{H}_{2} \mathrm{O} \rightarrow \mathrm{TiO}_{2} \cdot\left(\mathrm{e}^{-}+\right.$hole $\left.^{+}\right)+\mathrm{OH}^{-}+\mathrm{H}^{+}$.

hole $^{+}+$hole $^{+} \rightarrow \mathrm{OH}$

This highly oxidative $\mathrm{OH}^{\circ}$ degrades the organic molecules like bacteria, thereby killing the bacteria present in the water. After this, $\mathrm{OH}^{\circ}$ reacts with $\mathrm{H}^{+}$and the electron to reform $\mathrm{H}_{2} \mathrm{O}$ water back (Murugan and Ram 2018). 

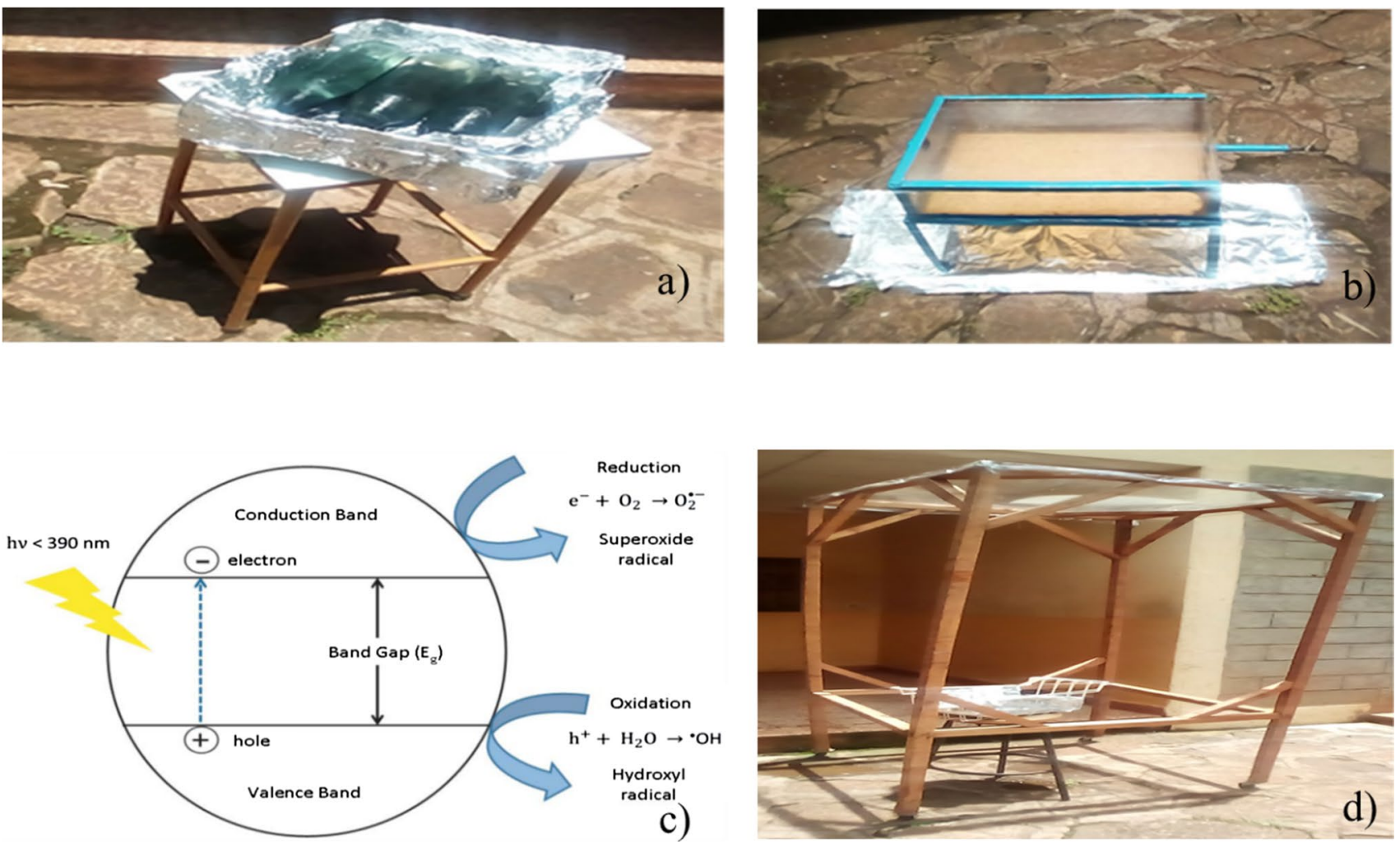

Fig. 1 Solar concentrators exposed to thermal and optical energy. a Half-blackened and aluminum-foil-coated glass bottle. b Photovoltaic box with aluminum foil. $\mathbf{c}$ Schematic representation of the mechanism of photocatalysis on titanium dioxide particles. $\mathbf{d}$ Aqua lens disinfection

$\mathrm{OH}^{0}+\mathrm{e}^{-} \rightarrow \mathrm{OH}^{-}$

\section{Aqua lens solar disinfection}

Aqua lens is a developing technology, with low design expenditure by locally available materials and ease for operation. As indicated in Fig. 1d, the structure contains four each $2.5-\mathrm{m}$-long stand woods and $75-100 \mathrm{~cm}$ in diameter plastic sheet to hold water which used as solar concentrator or lens, at the bottom four small tires connected for each stand to push or pull easily in the light direction to get focal point.

\section{Data analysis}

Data were analyzed using SPSS software for Windows Version 20 and Microsoft Excel tool 2013. The linear regression coefficient of determination and descriptive statistics of standard deviation were used to summarize the data. The log inactivation tests were conducted to compare inactivation rate of concentrators for each indicator organism (Dessie et al. 2014).

\section{Results}

\section{Moringa oleifera (MO) turbidity removal efficiency at low turbidity level}

As indicated in Fig. 2, the removal efficiency of M. oleifera became increased as of the water turbidity increases.

\section{UVA irradiation measurement for solar disinfection experiment}

All experiments were exposed for $3 \frac{1}{2} \mathrm{~h}$. to follow log inactivation of target indicator organisms. In three disinfection setups, all variables were measured within 30-min interval including UVA irradiation. In different weather conditions and solar exposure time, the UVA intensity was measured in the range of $645-1200 \mathrm{WUV} / \mathrm{m}^{2}$. 
Fig. 2 Moringa oleifera turbidity removal efficiency

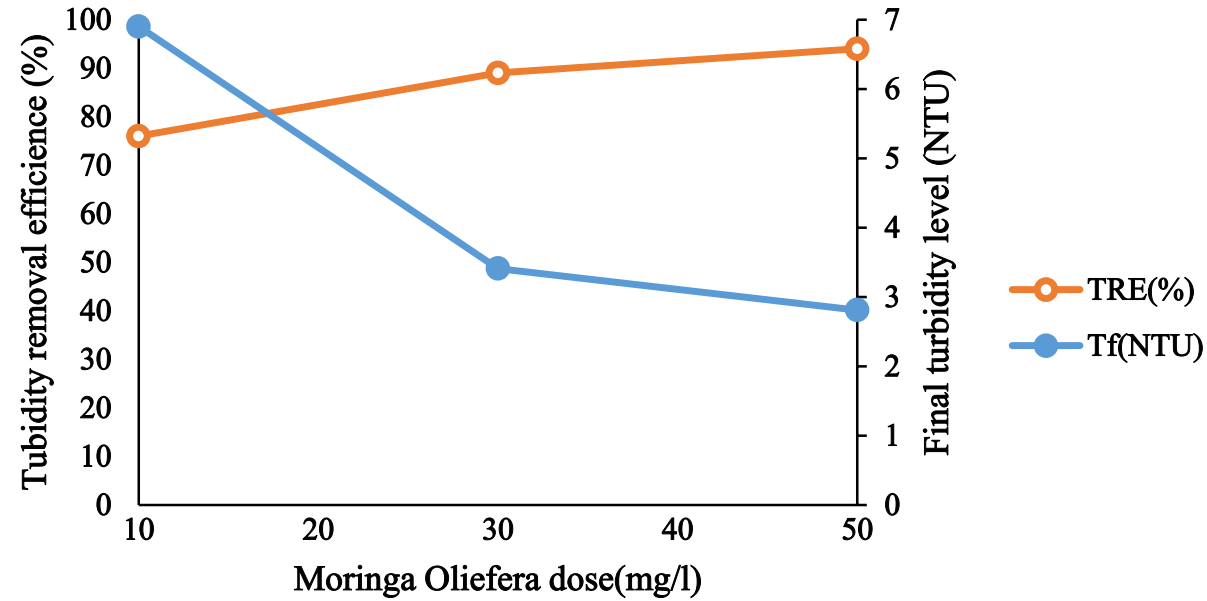

\section{Microbial inactivation of aqua lens ( $A L)$, photovoltaic (PV) and glass bottle (GB) at different turbidity levels}

\section{At 2.81 NTU turbidity level}

As shown in Fig. 3a, both AL and PV concentrators completely inactivated total coliforms before $2 \frac{1}{2} \mathrm{~h}$. with different $\log$ inactivation levels, but glass bottle continued to $3 \mathrm{~h}$ for complete inactivation. Figure $3 \mathrm{~b}$ presents aqua lens
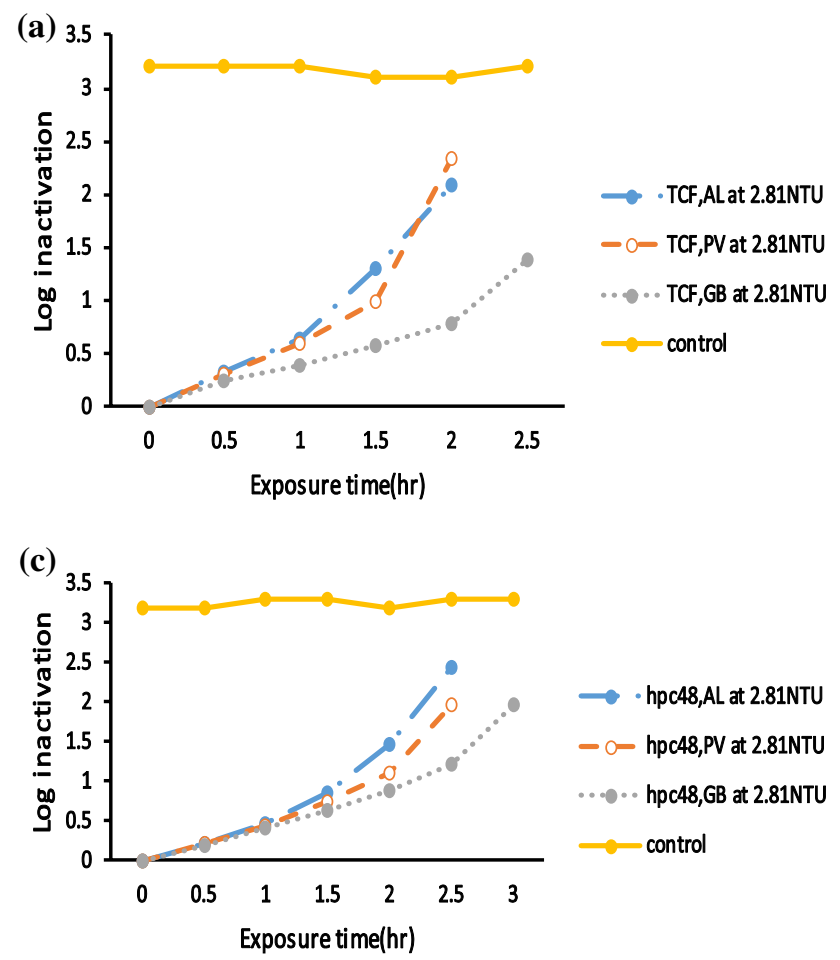

Fig. 3 Comparison of microbial inactivation between concentrators at 2.81 NTU turbidity level. a Comparison between concentrators for total coliform counts inactivation. b Comparison between concentra- concentrator inactivated $E$. coli before both $\mathrm{PV}$ and $\mathrm{GB}$ with $\log$ inactivation of $\log 2.5$ at one and half hour but completely inactivated before $2 \mathrm{~h}$. Except glass bottle, both concentrators completely inactivated heterotrophic plate counts before $3 \mathrm{~h}$. of solar exposure time (Fig. 3c).

\section{At 3.41 NTU turbidity level}

Glass bottles showed the least inactivation solar exposure time than others (Fig. 4a). On the other hand, both AL and

(b)

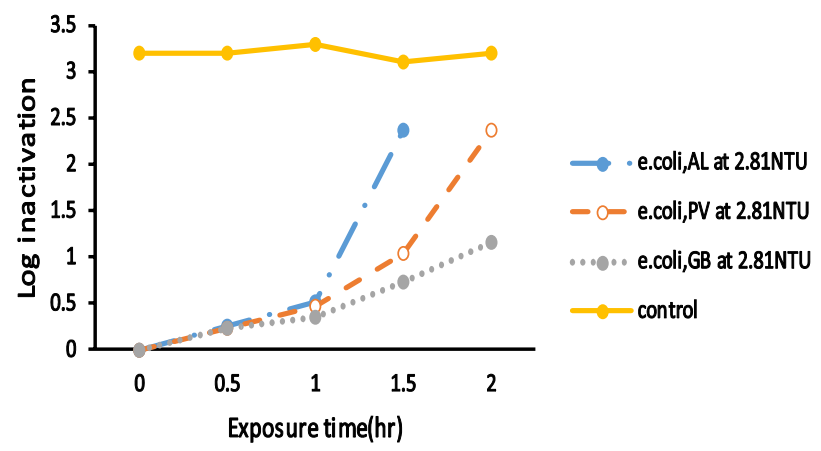

tors for E. coli inactivation. c Comparison between concentrators for heterotrophic plate count at $35^{\circ} \mathrm{C}$ for 48 -h inactivation 

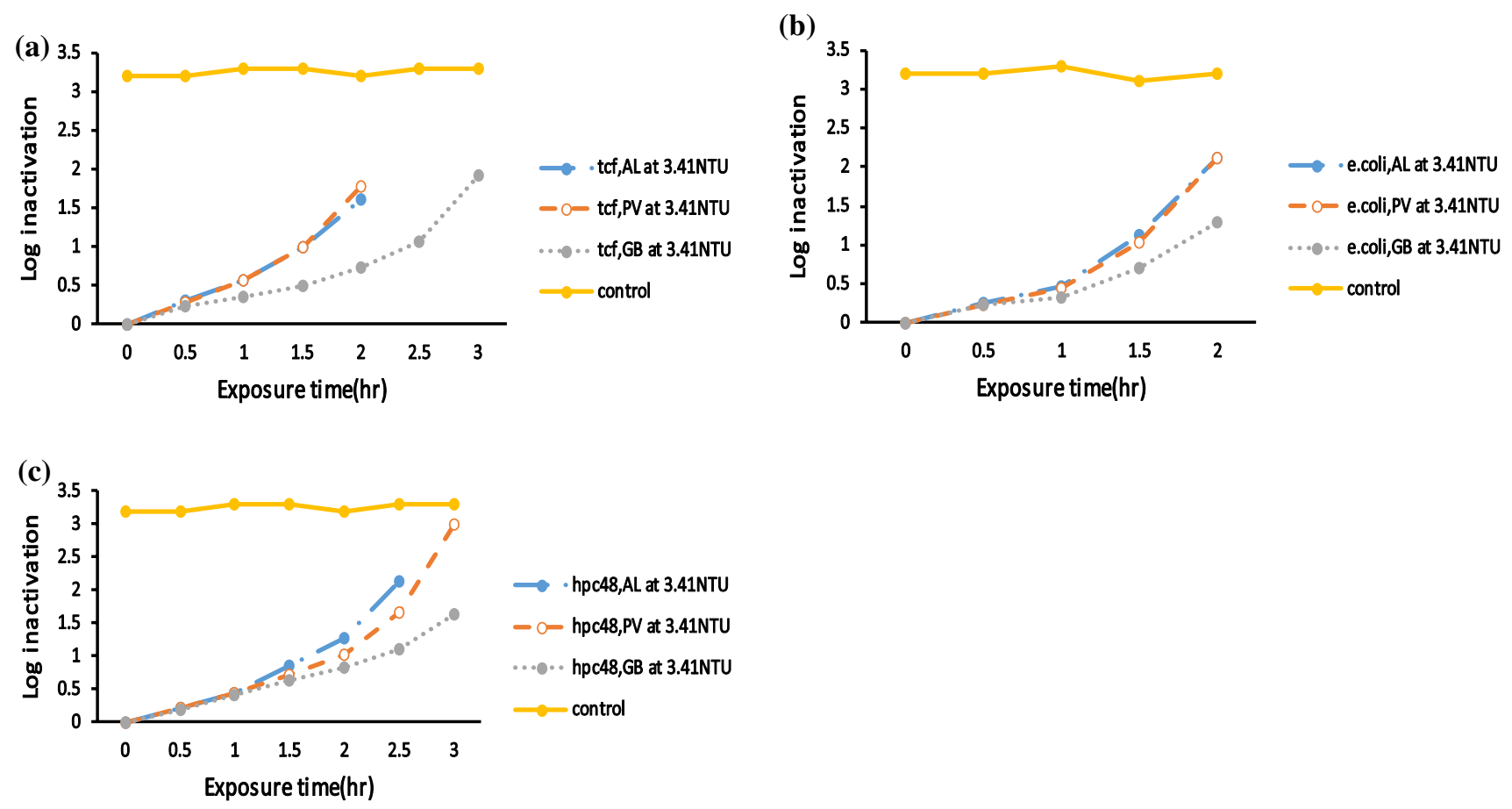

Fig. 4 Comparison of microbial inactivation between concentrators at 3.41 NTU turbidity level. a Comparison between concentrators for total coliform counts inactivation; $\mathbf{b}$ comparison between concentra-

PV concentrators completely inactivated before $2 \frac{1}{2}$. exposure time even if $\mathrm{PV}$ shows high log inactivation than $\mathrm{AL}$ for TCF counts at 3.41 NTU. As indicated in Fig. 4 b, all concentrators completely inactivated E. coli at similar solar exposure time with different log inactivation potential progresses at 3.41 NTU.

Figure $4 \mathrm{c}$ presents that photovoltaic and glass bottle concentrators completely inactivated after $\log 3$ and $\log 1.63$, respectively, but aqua lens inactivated totally before $3 \mathrm{~h}$. with $\log 2.14$.

\section{At 6.9 NTU turbidity level}

As shown in Fig. 5a, total coliforms extended to $3 \frac{1}{2} \mathrm{~h}$. in GB concentrator to inactivate completely, but both $\mathrm{AL}$ and $\mathrm{PV}$ inactivated entirely before $2 \frac{1}{2} \mathrm{~h}$. As shown in Fig. 5b, E. coli inactivated before $2 \frac{1}{2} \mathrm{~h}$. solar exposure time in both aqua lens and photovoltaic concentrators, while glass bottle inactivated completely at $3 \mathrm{~h}$. of solar exposure time. Heterotrophic plate counts were completely inactivated after $3 \mathrm{~h}$. in both PV and GB concentrators, but entirely inactivated before $3 \mathrm{~h}$. in AL concentrator as shown in Fig. 5c.

With regard to temperature concentrating potential of aqua lens, photovoltaic and glass bottle in similar solar exposure time showed different concentrating potentials. In aqua lens, high temperature was recorded at 6.9 NTU turbidity level as depicted in Fig. 6a-c.

tors for E. coli inactivation; c comparison between concentrators for heterotrophic plate count at $35^{\circ} \mathrm{C}$ for 48 -h inactivation

\section{Discussion}

\section{Moringa oleifera as pre-treatment for solar disinfection}

Moringa oleifera seed powder was used as a primary natural coagulant for low-cost household water treatment (Yahaya et al. 2011), at a range of turbidity levels. The removal efficiency of $M$. oleifera was increased when the raw water samples were highly turbid. For water sample of relatively high initial turbidity of $45.6 \mathrm{NTU}, M$. oleifera produced the best results with an average turbidity reduction of $94 \%$. Similar studies have been reported on turbidity removal efficiency and initial turbidity level (Abatneh et al. 2014).

In all three experimental setups, the water samples that contain relatively high turbidity of 6.9 NTU were achieved low inactivation rate of indicator organisms than the others. A different study that has been conducted in this area explains that inactivation rate clearly decreased when turbidity increased. Naturally dissolved organic matter may act as a photosensitizer and hence advance the inactivation process (Burgess et al. 2007). In aqua lens, E. coli inactivation showed negatively strong association $\left(R^{2}=0.98\right)$, and both $\mathrm{PV}$ and GB were associated negatively $\left(R^{2}=0.95\right)$ at different turbidity levels. High turbidity increased inactivation times and enhanced bacterial re-growth (Kehoe et al. 2001). 

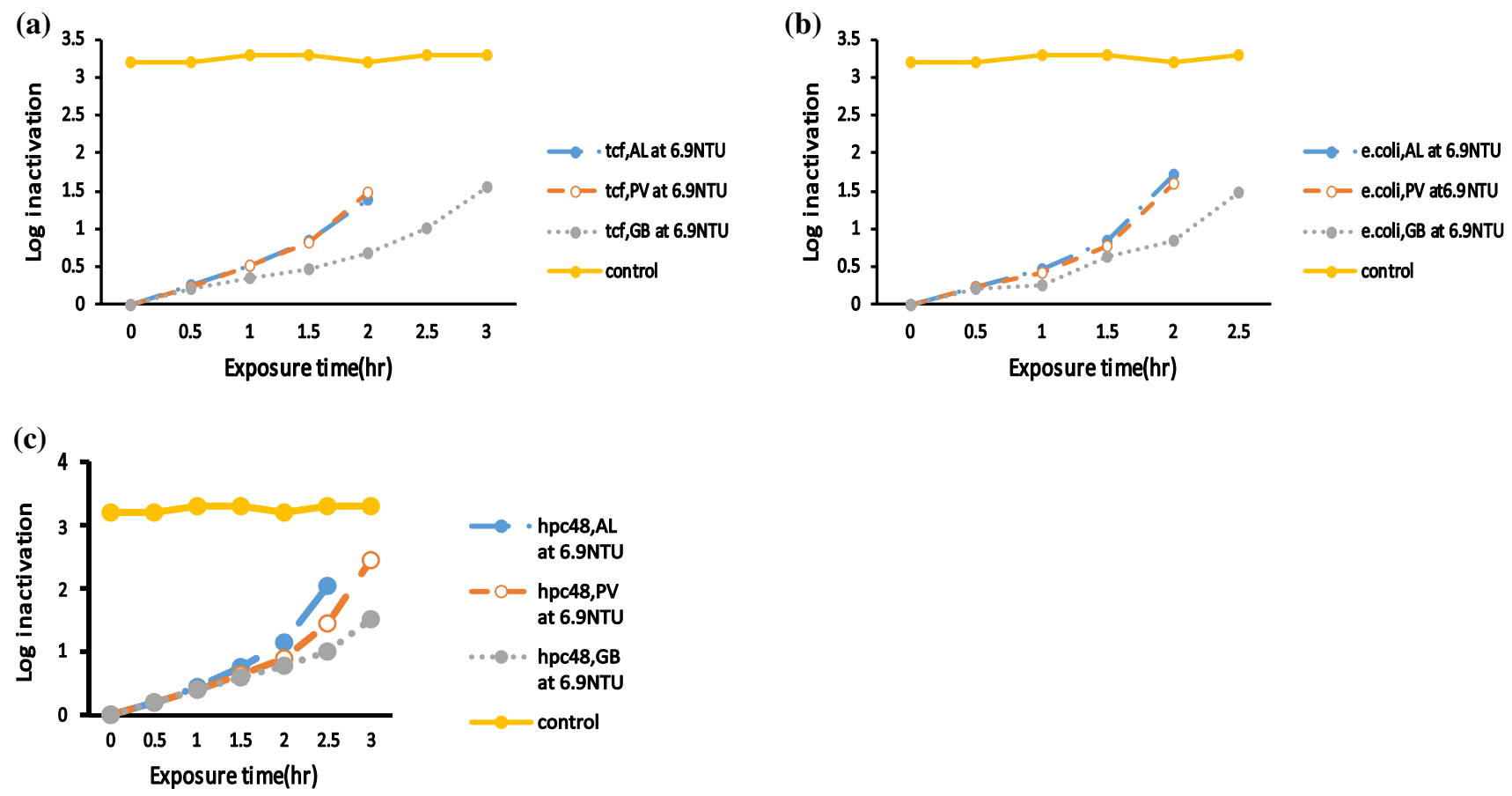

Fig. 5 Comparison of microbial inactivation between concentrators at 6.9 NTU turbidity level. a Comparison between concentrators for total coliform counts inactivation. b Comparison between concentra-

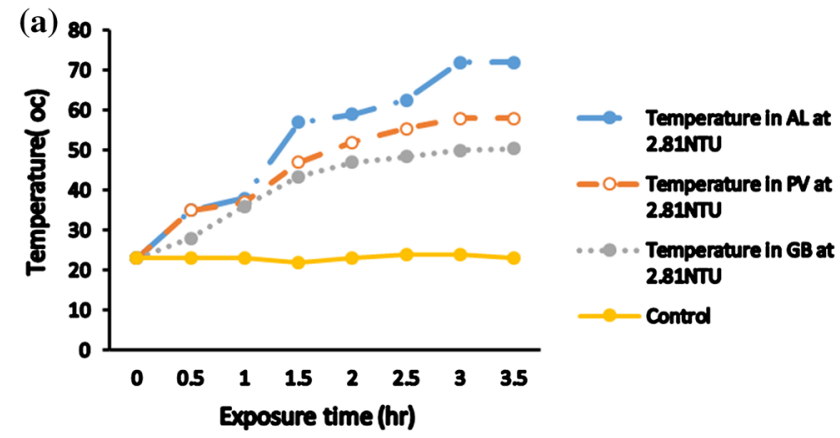

tors for $E$. coli inactivation. c Comparison between concentrators for heterotrophic plate count at $35^{\circ} \mathrm{C}$ for 48 -h inactivation
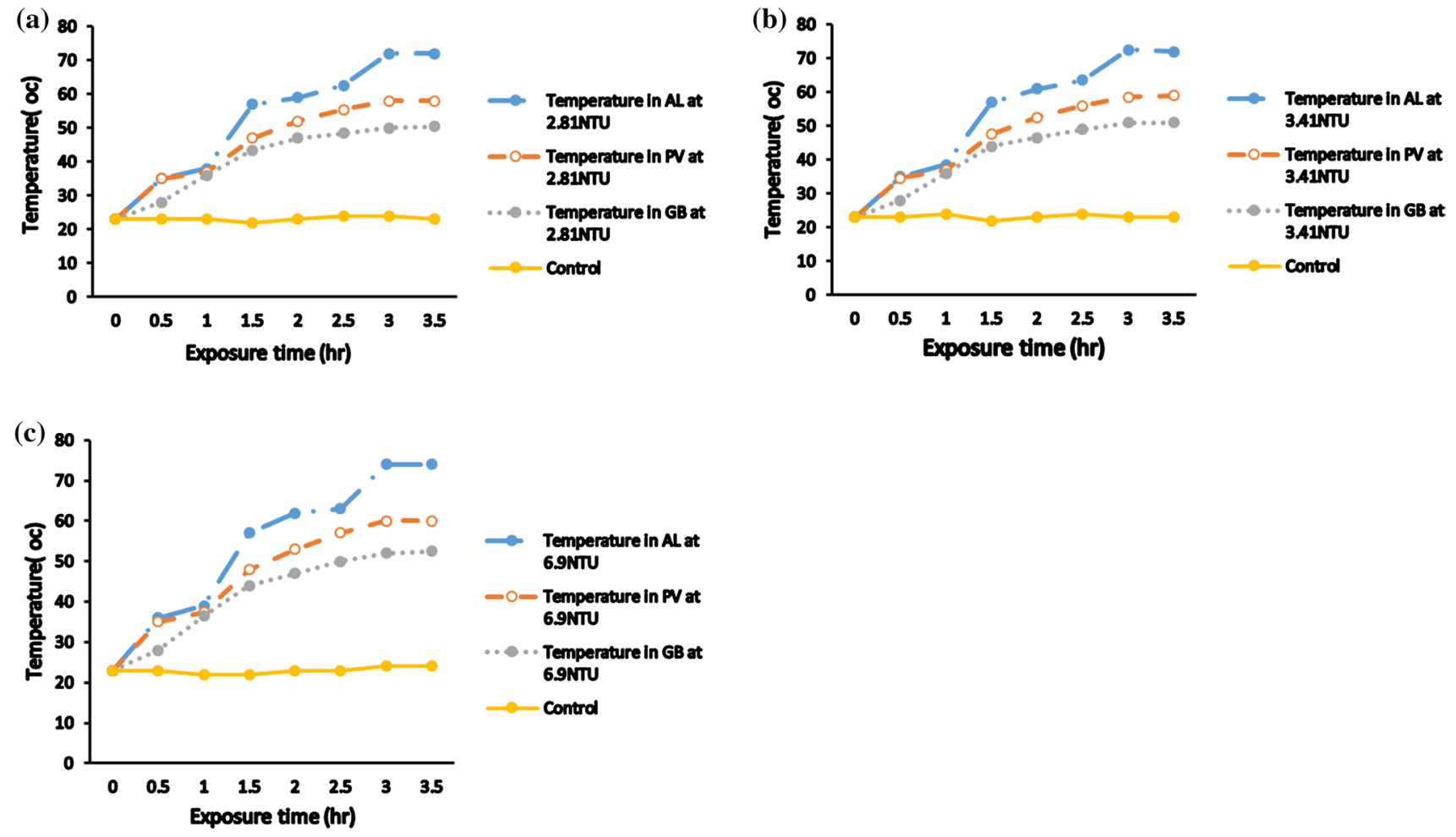

Fig. 6 Comparison between aqua lens, photovoltaic and glass bottle temperature concentrating potential at different turbidity levels. a

Temperature concentrating potential of concentrators at 3.41 NTU. c Temperature concentrating potential of concentrators at $6.9 \mathrm{NTU}$

Temperature concentrating potential of concentrators at 2.81 NTU. b 


\section{Solar irradiance measurement}

Under UVA exposure, the biocidal action of UVA has also been attributed to the production of reactive oxygen species which are generated from dissolved oxygen in water.

The photosensitization of molecules in the cell with any naturally occurring dissolved organic matter can absorb photons of wavelengths between 320 and $400 \mathrm{~nm}$, to induce photochemical reactions (Burgess et al. 2007; Byrne et al. 2011).

\section{Water temperature measurement}

As laboratory result indicated next to aqua lens, photovoltaic box disinfection showed relatively high inactivation rate than glass bottle, almost for all indicator organisms in short solar exposure time. Total coliforms were inactivated in $\mathrm{AL}$ $\left(\mathrm{SD}=15.8^{\circ} \mathrm{C}, R^{2}=0.92\right)$ followed by $\mathrm{PV}$ inactivation temperature association $\left(\mathrm{SD}=11.6^{\circ} \mathrm{C}, R^{2}=0.90\right)$, and the $\mathrm{GB}$ concentrator was inactivated $\left(\mathrm{SD}=10.9{ }^{\circ} \mathrm{C}, R^{2}=0.70\right)$ at turbidity level of $3.41 \mathrm{NTU}$. The role of semiconductor $\mathrm{TiO}_{2}$ with natural organic matter to form highly disinfectants reactive oxygen species and the high light transmittance potential of acrylic glass sheet supports to attain high inactivation rate than GB (Mcguigan et al. 2012; Murugan and Ram 2018).

Water temperature was raised through progress when solar exposure time becomes increased. All disinfection setups were measured slightly different from water temperature concentrating potentials. The aqua lens measured highest water temperature $\left(74^{\circ} \mathrm{C}\right)$ followed by photovoltaic $\left(60^{\circ} \mathrm{C}\right)$ and the glass bottle $\left(52.5^{\circ} \mathrm{C}\right)$ which was the lowest water temperature recorded in this study at different turbidity levels. Similar studies have been investigated that glass bottle is able to concentrate $45-50{ }^{\circ} \mathrm{C}$ water temperature at different weather conditions with global irradiance of $800 \mathrm{~W} / \mathrm{m}^{2}$ (Navntoft et al. 2008; Mcguigan et al. 2012).

Aluminum foil was used at back side of half-blackened GB, PV and AL disinfection setups. High reflective power of aluminum foil to concentrators was elevated water temperature at short exposure time. Experimental studies confirmed that aluminum foil back-coated solar concentrators increased disinfection rate constants by a factor of twofold (Navntoft et al. 2008; Kehoe et al. 2001; Rengifo-herrera et al. 2011; Mcguigan et al. 2012).

In this study, dissolved oxygen in the water container ranged between 6.35 and $8.74 \mathrm{mg} / \mathrm{L}$, and as investigated in laboratory experiment dissolved oxygen was inversely related to water temperature $\left(R^{2}=0.78\right)$. A similar study explained that the amount of dissolved oxygen quickly utilized in some stages of the reaction due to increment of temperature (Byrne et al. 2011; Giannakis et al. 2014).

All experiments were exposed to both optical (UVA light) and thermal (infrared heat) electromagnetic spectrum inactivation system. The inactivation result which is shown above is direct synergism effect of light and heat. However, bactericidal action was evidenced at temperatures above $40-45^{\circ} \mathrm{C}$ with a synergistic SODIS process (Byrne et al. 2011; Mcguigan et al. 2012; Helali et al. 2013; Giannakis et al. 2014). The $E$. coli, total coliforms and heterotrophic plate counts inactivation experiments were conducted at natural waters source in three separate turbidity levels $(2.81,3.41$ and $6.9 \mathrm{NTU})$. The relation between three indicator organisms like $E$. coli is assumed to be a subset of total coliforms, which is a subset of heterotrophic plate counts bacteria (Wilson and Andrews 2011).

In three and half hour solar disinfection exposure time almost in all experiments, $E$. coli were inactivated prior than total coliforms and heterotrophic plate counts with complete inactivation range of $2 \mathrm{~h}(2.81 \mathrm{NTU})$ in aqua lens and $3 \mathrm{~h}(6.9$ NTU) in glass bottle disinfection system with the association $\left(\mathrm{SD}=10.8^{\circ} \mathrm{C}, R^{2}=0.81\right)$. However, $E$. coli were inactivated in aqua lens concentrator $\left(\mathrm{SD}=14.1^{\circ} \mathrm{C}, R^{2}=0.91\right)$, which shows high association between $E$. coli inactivation and water temperature. Different studies support this complete inactivation rate with indicated exposure time range, keeping other variables similar to this result (Mcguigan et al. 2012).

Mesophilic characteristics of $E$. coli thrive between 20 and $45^{\circ} \mathrm{C}$, but for the temperature beyond the range there is a thermal tension exerted to the cells, affecting the cell wall in addition to destroying the proteins and nucleic acids, leading to death of bacteria (Giannakis et al. 2014). Total coliforms and HPC completely inactivated at $2 \frac{1}{2}$ and $3 \mathrm{~h}$. in aqua lens solar concentrator with the association of $\left(\mathrm{SD}=15.3{ }^{\circ} \mathrm{C}, R^{2}=0.90\right)$ and $\left(\mathrm{SD}=16.0{ }^{\circ} \mathrm{C}, R^{2}=0.77\right)$ at $2.81 \mathrm{NTU}$ turbidity level, respectively. Total coliforms were recorded similar inactivation time in PV disinfection system; however, 30 additional minutes were required to inactive heterotrophic plate counts completely, considering at different turbidity levels (Wilson and Andrews 2011).

\section{Conclusions}

The disinfection potential of concentrators was increased at $2.81 \mathrm{NTU}$. Aqua lens solar disinfection was shown to be an effective household water treatment system. Heterotrophic plate counts were more resistant than the other coliforms in SODIS treatment within similar inactivation exposure time.

Acknowledgements We are grateful to Jimma University for financial and logistic support.

Open Access This article is distributed under the terms of the Creative Commons Attribution 4.0 International License (http://creativeco mmons.org/licenses/by/4.0/), which permits unrestricted use, distribution, and reproduction in any medium, provided you give appropriate credit to the original author(s) and the source, provide a link to the Creative Commons license, and indicate if changes were made. 


\section{References}

Abatneh Y, Sahu O, Yimer S (2014) Purification of drinking water by low cost method in Ethiopia. Appl Water Sci 4(4):357-362. https ://doi.org/10.1007/s13201-013-0151-9

Almeida J, Félix A, Figueiredo RAA (2015) Drinking-water microbiological quality survey in the district of Aveiro (Portugal): a nine-year surveillance study (2000-2008). 3(March), pp 38-44

Bekele T, Leta S (2016) Water supply and health: drinking water and sanitation coverage in Ethiopia 1990-2015 review. Int J Environ Agri Biotec 1(1):11-24

Bosshard F, Bucheli M, Meur Y, Egli T (2010) The respiratory chain is the cell's Achilles' heel during UVA inactivation in Escherichia coli. Microbiology 156(7):2006-2015

Burgess L, Gara A, Le B, Letkeman S (2007) The role of reactive oxygen species in the solar disinfection (SODIS) system of water contaminated with Escherichia coli and Salmonella enterica serovar Typhimurium. J Exp Microbiol Immunol 11:35-41

Dessie A, Alemayehu E, Mekonen S, Legesse W, Kloos H, Ambelu A (2014) Solar disinfection: an approach for low-cost household water treatment technology in southwestern Ethiopia. J Environ Health Sci Eng 12:1-6

Byrne JA, Fernandez-Ilbanez, PA, Patrick SM (2011) Photocatalytic enhancement for solar disinfection of water: a review. Int J Photoenergy 2011:1-12

Fontan-Sainz M, Gomez-Couso H, Fernandez-Ibanez P, Ares-Mazas E (2012) Evaluation of the solar water disinfection process (SODIS) against cryptosporidium parvum using a 25-1 static solar reactor fitted with a compound parabolic collector (cpc). Am J Trop Med Hyg 86(2):223-228. https://doi.org/10.4269/ajtmh.2012.11-0325

Giannakis S, Darakas E, Escalas-Canellas A, Pulgarin C (2014) The antagonistic and synergistic effects of temperature during solar disinfection of synthetic secondary effluent. J Photochem Photobiol A Chem 280:14-26

Gomez-Couso H, Fontan-Sainz M, Sichel C, Fernandez-Ibanez P, AresMazas E (2009) Efficacy of the solar water disinfection method in turbid waters experimentally contaminated with Cryptosporidium parvum oocysts under real field conditions. Trop Med Int Health 14(6):620-627

Helali S, Polo-Lopez, MI, Fernandez-Ibanez P, Ohtani B, Amano F, Malato S, Guillard C (2013) Solar photocatalysis: a green technology for $E$. Coli contaminated water disinfection. Effect of concentration and different types of suspended catalyst. J Photochem Photobiol A 276:31-40

Kehoe SC, Joyce TM, Ibrahim P, Gillespie JB, Shahar RA, McGuigan KG (2001) Effect of agitation, turbidity, aluminium foil reflectors and container volume on the inactivation efficiency of batchprocess solar. Water Res 35(4):1061-1065

Lea M (2010) Bioremediation of turbid surface water using seed extract from Moringa oleifera Lam. (Drumstick) Tree. (February), pp $1-14$
Mcguigan KG, Joyce TM, Conroy RM, Gillespie JB, Elmore-Meegan M (1998) Solar disinfection of drinking water contained in transparent plastic bottles: characterizing the bacterial inactivation process. J Appl Microbiol 84:1138-1148

Mcguigan KG, Conroy RM, Mosler HJ, du Preez M, Ubomba-Jaswa E, Fernandez- Ibanez P (2012) Solar water disinfection (SODIS): a review from bench-top to roof-top. J Hazard Mater 235:29-46

Myers DN (2003) Fecal indicator bacteria. 7:1-64

Navntoft C, Conroy RM, Mosler HJ, du Preez M, Ubomba-Jaswa E, Fernandez-Ibanez P (2008) Effectiveness of solar disinfection using batch reactors with non-imaging aluminium reflectors under real conditions: natural well-water and solar light. J Photochem Photobiol B Biol 93:155-161

Murugan R, Ram CG (2018) Energy efficient drinking water purification system using $\mathrm{TiO}_{2}$ solar reactor with traditional methods. Mater Today-Proc 5(2018):415-421

Reed RH (1997) Solar inactivation of faecal bacteria in water: the critical role of oxygen. Lett Appl Microbiol 24:276-280

Rengifo-herrera JA, Rengifo-herrera A, We J (2011) Solar disinfection of wild Salmonella $\mathrm{Sp}$. In natural water with a $18 \mathrm{~L} \mathrm{CPC}$ photoreactor: detrimental effect of non-sterile storage of treated water solar disinfection of wild Salmonella $\mathrm{Sp}$. In natural water with a 18 L CPC photoreactor : detrimental effect of non-sterile storage of treated water (2015)

Sobsey MD (2002) Managing water in the home: accelerated health gains from improved water supply. Department of Protection of the Human Environment, World Health Organization, Geneva pp $1-70$

Sobsey MD, Stauber CE, Casanova LM, Brown JM, Elliott MA (2008) Point of use household drinking water filtration: a practical, effective solution for providing sustained access to safe drinking water in the developing world. Environ Sci Technol 42(12):4261-4267

Stillings D, Herzig BR (1998) Comparative Assessment of the newly developed simplate ${ }^{\text {tm }}$ method with the existing EPA-approved pour plate method for the detection of heterotrophic plate count bacteria in ozone-treated drinking water, pp 0-13

UNICEF (2016) One is too many ending child deaths from pneumonia and diarrhoea. https://www.unicef.org/publications/index93020 .html

Wilson SA, Andrews SA (2011) Impact of a natural coagulant pretreatment for colour removal on solar water disinfection (SODIS). J Nat Sanit Hyg Dev 1:57-67

Yahaya DS, Enemaduku AM, Eru EO (2011) The use of Moringa seed extract in water purification. Int j Res 2(4):1265-1271

Publisher's Note Springer Nature remains neutral with regard to jurisdictional claims in published maps and institutional affiliations. 